\title{
Pendampingan Penilaian Kesiapan Penerapan Rekam Medis Elektronik Menggunakan Metode DOQ-IT di RS Condong Catur Sleman
}

Praptana $^{1}$, Kori Puspita Ningsih ${ }^{2}$, Sugeng Santoso ${ }^{3}$, Imaniar Sevtiyani ${ }^{4}$

${ }^{1-4}$ Rekam Medis dan Informasi Kesehatan, Fakultas Kesehatan, Universitas Jenderal Achmad Yani, Yogyakarta, Indonesia

e-mail: ${ }_{1}^{1}$ praptana@gmail.com, ${ }^{2}$ puspitakori@gmail.com, ${ }^{3}$ sugengsantoso903@gmail.com, ${ }^{4}$ isevtiyani@gmail.com

\begin{abstract}
ABSTRAK
Dalam upaya meningkatkan kinerja, RS Condong Catur berencana menerapkan aplikasi Sistem Manajemen Informasi Rumah Sakit (SIMRS) berbasis Rekam Medis Elektronik (RME). Melalui SIMRS berbasis RME ini diharapkan mampu menyajikan berbagai informasi yang dibutuhkan dengan cepat dan lengkap. Kesiapan penerapan rekam medis elektronik penting dilakukan supaya aplikasi dapat berjalan dengan optimal dan tidak menimbulkan masalah di kemudian hari. Metode Doctor's Office Quality-Information Technology (DOQIT) merupakan salah satu metode untuk menganalisis tingkat kesiapan penerapan sistem informasi berbasis rekam medis elektronik. Metode ini sangat tepat digunakan untuk menganalisis kesiapan sebelum sebuah aplikasi berbasis elektronik dioperasikan. Metode DOQ-IT menekankan pada empat komponen utama dalam suatu sistem kerja organisasi yaitu sumberdaya manusia, kepemimpinan tata kelola, budaya organisasi dan infrastruktur. Penerapan rekam medis elektronik tidak dapat berjalan maksimal apabila dari ke empat komponen ini belum siap. Melalui metode ini diharapkan akan mengetahui masalah yang dihadapi sehinga dapat dicari solusi segera untuk menanganinya. Pengabdian kepada masyarakat dilakukan dengan cara memberikan penyuluhan terkait pendampingan tatacara melakukan penilaian kesiapan penerapan RME mengunakan metode DOQ-IT kepada pimpinan dan staf RS Condong Catur. Kegiatan berjalan lancar. Pada awalnya Pimpinan dan staff RS Condong Catur belum mengetahui pentingnya penilaian kesiapan dalam proses penerapan RME. Setelah pendampingan penilaian menggunakan DOQ-IT melalui kegiatan Pengabdian Kepada Masyarakat ini diketahui bahwa skor kesiapan sebesar 69,38 yang berarti RS Condong Catur cukup siap menerapkan SIMRS berbasis rekam medis elektronik.
\end{abstract}

KATA KUNCI: Penerapan, Rekam medis elektronik; DOQ-IT, Rumah sakit.

\section{Pendahuluan}

Teknologi informasi menjadi bagian penting dalam berbagai aspek kehidupan termasuk pada bidang kesehatan. Pada fasilitas pelayanan kesehatan (fasyankes) teknologi informasi bermanfaat untuk memudahkan proses manajemen data kesehatan yang bersifat kompleks. Teknologi informasi dapat membantu dalam proses pengumpulan, pengolahan dan penyajian data [1]. Sistem Informasi merupakan sebuah alat atau sarana yang bertujuan untuk mengolah data menjadi informasi yang dapat digunakan oleh pengambil keputusan secara cepat dan tepat [2]. Pada Permenkes Nomor 82 Tahun 2013 tentang Sistem Informasi Manajemen Rumah Sakit, dalam aturan tersebut setiap rumah sakit wajib menyelengarakan Sistem Informasi Manajemen Rumah Sakit (SIMRS). Dalam pasal 4 ayat 2 menegaskan pengelolaan dan pengembangan SIMRS juga harus mampu meningkatkan dan mendukung proses pelayanan kesehatan di rumah sakit yang 
meliputi kecepatan, akurasasi, integrasi, peningkatan pelayanan, peningkatan efisiensi, kemudahan pelaporan dalam pelaksanaan pelaporan. SIMRS mampu meningkatkan kecepatan mengambil keputusan, akurasi dan kecepatan identifikasi masalah dan kemudahan dalam penyusunan strategi dalam pelaksanaan manajerial. SIMRS mampu meningkatkan budaya kerja, transparasi, koordinasi antar unit, pemahaman sistem dan pengurangan biaya administrasi dalam pelaksanaan organisasi [3].

Saat ini RS Condong catur menggunakan rekam medis manual, sehingga proses pengolahan menjadi informasi kesehatan juga manual. Penerapan sistem yang manual memiliki kelemahan, seperti membutuhkan waktu lama untuk mengolah menjadi suatu informasi dan keakuratan juga kurang dapat diterima karena dapat berpotensi terjadi kesalahan [4]. Dalam upaya meningkatkan kinerja dan mendukung proses pelayanan kesehatan, RS Condong Catur berencana mengadakan SIMRS yang sudah berbasis Rekam Medis Elektronik (RME). SIMRS berbasis RME akan dapat membantu meningkatkan pelayanan apabila dirancang dengan baik, tetapi dapat juga memperburuk pelayanan jika tidak dipersiapkan dengan benar.

Adapun dalam kesiapan penerapan rekam medis elektronik penting dilakukan supaya aplikasi dapat berjalan dengan optimal dan tidak menimbulkan masalah di kemudian hari. Pada umumnya penerapan RME masih mengalami beberapa kendala seperti di RSUD Kota Yogyakarta yang sudah menerapkan SIMRS dengan pengembangan RME tetapi belum dimanfaatkan dengan optimal karena tidak adanya perencanaan yang jelas [5].

Salah satu cara untuk mengetahui tingkat kesiapan pelaksanaan Electronic Health Record (EHR) yakni dengan menggunakan EHR Assessment and Readiness Starter Assessment oleh Doctor's Office Quality-Information Technology (DOQ-IT). EHR Assessment and Readiness Starter Assessment oleh DOQ-IT adalah instrumen penilaian penerapan teknologi IT di instansi kesehatan yang dibuat atas inisiatif nasional untuk mempromosikan adopsi dari EHR oleh DOQ-IT dari Healthcare Information and Management Systems Society (HIMSS). DOQ-IT merupakan salah satu metode untuk menganalisis tingkat kesiapan penerapan sistem informasi berbasis rekam medis elektronik [5]-[7]. Dari hasil analisis kesiapan RME tersebut dapat digunakan sebagai bahan pertimbangan penyusunan "road map" dan memberikan gambaran keberlanjutan pengembangan rekam kesehatan elektronik [5].

RS Condong Catur berencana menerapkan SIMRS berbasis RME. Akan tetapi sampai saat ini belum dilakukan peniliaan tingkat kesiapan penerapan RME. Dimana, keberhasilan penerapan SIMRS berbasis RME tidak dapat lepas dari kesiapan yang baik. Sampai saat ini belum diketahui apakah sumberdaya manusia, tata kelola kepemimpinan, budaya organisasi dan infrastruktur yang ada mendukung dalam penerapan SIMRS berbasis RME. Analisis kesiapan penerapan sebuah sistem aplikasi baru sangat penting karena merupakan kunci utama keberhasilan penerapan sebuah sistem informasi. Hal inilah yang memicu untuk melakukan Pengabdian Kepada Masyarakat(PKM) terkait analisis kesiapan penerapan SIMRS berbasis RME mengunakan metode DOQ-IT di Rumah Sakit Condong Catur.

\section{Metode}

Kegiatan pengabdian ini dilaksanakan di RS Condong Catur, yang beralamat di Jl. Manggis No.6, Gempol, Condongcatur, Kec. Depok, Kabupaten Sleman, Daerah Istimewa Yogyakarta. Kegiatan PKM ini melibatkan tim dosen, laboran dan mahasiswa, yang terdiri dari 3 dosen, 1 laboran dan 2 mahasiswa. Praptana...........Pendampingan Penilaian Kesiapan Penerapan Rekam Medis 
Pelaksanaan pengabdian ini dilaksanakan dalam kurun waktu 3 (tiga bulan dari bulan Maret - Mei 2021. Metode yang digunakan dalam kegiatan pengabdian kepada masyarakat ini sebagai berikut:

2.1. Tahap Persiapan: Tahap persiapan yang dilakukan adalah studi pendahuluan dengan wawancara kepada petugas rekam medis di RS Condong Catur . Setelah itu, tim mulai merumuskan masalah kemudian menyusun proposal Pengabdian Kepada Masyarakat. Kegiatan selanjutnya adalah menyusun materi untuk kegiatan penyuluhan

\subsection{Tahap Pelaksanaan:}

a. Kegiatan diawali dengan tim PKM menyampaikan materi terkait tahaptahap dalam membuat sebuah aplikasi SIMRS.

b. Kegiatan dilanjutkan dengan sesi penilaian kesiapan. Peserta mengisi google form yang sudah diberi pertanyaan sesuai ceklist pagu dari DOQIT. Metode DOQ-IT digunakan untuk menganalisis tingkat kesiapan penerapan sistem informasi berbasis rekam medis elektronik. Data dari hasil analisis DOQ-IT bermanfaat sebagai bahan pertimbangan RS Condong Catur untuk menyusun "road map" dan memberikan gambaran keberlanjutan pengembangan rekam kesehatan elektronik.

c. Peserta dalam memberikan penilian diceklist tersebut dipandu oleh tim PKM. Tim PKM menjelaskan setiap pertanyaan, dan isi disetiap pilihan agar peserta mampu menilai posisi rumah sakit lebih akurat.

d. Para peserta pengabdian kepada masyarakat berdiskusi sesuai unit kerja masing-masing menilai tingkat kesiapan Rumah Sakit menerapkan RME. Dari masing-masing kelompok, mencoba memberikan penilian terhadap kondisi RS Condong Catur terkait sumberdaya manusia, kepemimpinan, budaya organisasi, dan infrastruktur.

\subsection{Tahap akhir}

Pada akhir kegiatan PKM ini dilakukan evaluasi tanya jawab dan disukusi Selanjutnya data kuesioner DOQ-IT dari kegiatan PKM diolah untuk diketahui skor kesiapan. Semua dokumentasi dan proses kegiatan PKM disusun dalam bentuk laporan akhir dan publikasi.

\section{Hasil dan Pembahasan}

Bahan atau materi berupa softcopy power point diberikan kepada seluruh staff yang hadir yang hadir saat penyuluhan. Alat yang digunakan pada kegiatan PKM ini adalah komputer atau notebook, Zoom meeting, jaringan internet/Modem, dan kuesioner DOQ-IT. Sasaran kegiatan pengabdian ini adalah Direktur Rumah Sakit, Kepala Unit, Kasi Rekam Medis, Staff Rekam Medis dan perwakilan Staff masing-masing unit Rumah Sakit Condong Catur yang berjumlah sekitar 30 peserta.

Secara keseluruhan, kegiatan pengabdian masyarakat ini berjalan dengan lancar. Sambutan dari seluruh petugas rumah sakit juga sangat baik, ramah, dan bekerjasama. Antusiasme dari peserta juga cukup baik, hal ini bisa terlihat mulai dari awal kegiatan sampai rangkaian kegiatan selesai. Kegiatan penyuluhan oleh mahasiswa sebagai MC. Mahasiswa lain bertugas mendokumentasikan kegiatan. Sambutan diberikan oleh Direktur RS Condong Catur, yang menyampaikan ucapan terimakasih tas penyelenggaraan kegiatan pengabdian ini. Hal ini dikarenakan materi yang akan disampaikan sangat diperlukan oleh pihak rumah sakit dalam rangka persiapan penerapan RME. Selanjutnya ketua tim PKM memperkenalkan seluruh anggota PKM, serta maksud dan tujuan kegiatan PKM.

Materi disampaikan terkait tahap-tahap pengembangan SIMRS, meliputi perencanaan, analisis, desain, implementasi dan maintenance. Didalam tahap 
perencanaan meliputi analisis kesiapan, analisis kebutuhan dan perencanaan perancangan. Adapun komponen komponen yang perlu diperhatikan dalam tahap persiapan SIMRS diantaranya meliputi: sumber daya manusia, kepemimpinan, budaya organisasi dan infrastruktur. Hal ini sesuai penelitian lain yang menyampaikan bahwa untuk menentukan road map dan keberlanjutan program pengembangan rekam medis elektronik dibutuhkan analisis kesiapan kondisi sumberdaya manusia, budaya, tata kelola kepemimpnan serta infrastruktur [5], [6], [8], [9].

Setelah penyampaian materi dilanjutkan sesi penilaian dan sesi diskusi. Dalam sesi penilaian tersebut, peserta mengisi google form yang sudah diberi pertanyaan sesuai ceklist pagu dari DOQ-IT. Peserta dalam memberikan penilian diceklist tersebut dipandu oleh tim PKM. Tim PKM menjelaskan setiap pertanyaan, dan isi disetiap pilihan agar peserta mampu menilai posisi rumah sakit lebih akurat. Ceklis pagu penilian yang digunakan yaitu mengunakan Metode doctor's office quality-information technology (DOQ-IT). Para peserta pengabdian kepada masyarakat berdiskusi sesuai unit kerja masing-masing menilai tingkat kesiapan rumah sakit menerapkan RME. Dari masing-masing kelompok, mencoba memberikan penilian terhadap kondisi Rumah Sakit Condong Catur terkait sumberdaya manusia, kepemimpinan, budaya organisasi, dan infrastruktur (tabel $1)$.

Tabel 1. Hasil Penilaian Responden

\begin{tabular}{lccc}
\hline Komponen Penilian & Nilai & Jumlah Pertanyaan & Rata-Rata Nilai \\
\hline SDM & 14.18 & 6 & 2.36 \\
\hline Budaya Kerja Organisasi & 25.70 & 11 & 2.34 \\
\hline Kepemimpinan & 20.06 & 8 & 2.51 \\
\hline Insfrastruktur & 9.44 & 4 & 2.36 \\
\hline Total & 69.38 & & 2.39 \\
\hline
\end{tabular}

Dari tabel 1 dapat disampaikan bahwa rata-rata nilai dari keempat komponen sebesar 2,39 yang menunjukkan bahwa RS Condong Catur cukup siap dalam mengembangan RME. Penilaian kesiapan pada setiap komponen variabel pada kisaran 2-3 memeberikan makna cukup siap. Semakin tinggi skor, menunjukkan tingkat kesiapan yang lebih tinggi untuk masing-masing elemen [7]. Dari keempat komponen tersebut nilai tertinggi di komponen kepemimpinan (skor: 2,51). Keberhasilan proses impelemntasi RME sangat dipengaruhi oleh dukungan pimpinan yang kuat, yang disertai dengan adanya keaktifan user khususnya staff klinis dalam tahap desain dan implementasi, yang selanjutnya diikuti dengan adanya pelatihan staff serta perencanaan yang sesuai dengan jadwal dan anggaran [5]. Adanya kebijakan pimpinan berpengaruh besar pada kesuksesan penerapan RME. Hal ini dikarenakan ada motivasi yang kuat dari staff untuk patuh pada ketentuan dari Pimpinan dan peningkatan semangat menerapkan RME juga diikuti dengan adanya reward [7].

Selanjutnya dari tabel 1 juga dapat disampaikan bahwa komponen SDM dan Infrastruktur mendapatkan rata-rata nilai yang sama (skor: 2,36). SDM selaku user dari pengguna RME maupun sebagai bagian dari penyusun kebijakan akan sangat menetukan keberhasilan dari pengembangan RME. SDM tersebut meliputi staf medis dan administrasi, serta jajaran manajemen. Hasil penelitian sebelumnya juga menunjukan bahwa RME mamp meningkatkan kualitas pelayanan namun harus didukung dengan sistem kerja yang jelas dan SDM IT yang handal [5]. Selanjutnya, pada tahap pembangunan infrastruktur juga perlu memperhatikan persyaratan guna menjamin privasi dan keamanan data serta akuntabilitas. Langkah-langkah yang perlu diperhatikan pada saat merancang diantaranya membentuk tim keamanan, memperhitungkan resiko, membuat kebijakan dan

Praptana...........Pendampingan Penilaian Kesiapan Penerapan Rekam Medis 
SOP, menerapkan kontrol, membuat pelatihan-pelatihan pendukung, dan monitoring proses [10]

Sementara itu hasil analisis DOQ-IT menunjukkan kesiapan terkait budaya kerja organisasi mendapatkan posisi terendah (skor: 2,34). Dalam tahap awal penerapan RME akan terjadi pergeseran budaya yang akan berdampak pada fisik dan fisiologis [11]. Budaya kerja organisasi yang baik adalah kemampuan pimpinan dalam menetapkan suatu kebijakan, Standar Operasional Prosedur maupun proses bisnis yang perlu diiketahui serta mampu menggerakkan staff dalam mengimpementasikan RME [9].

Berikut hasil analisis kesiapan penerapan RME di RS Condong Catur (gambar $1)$ :

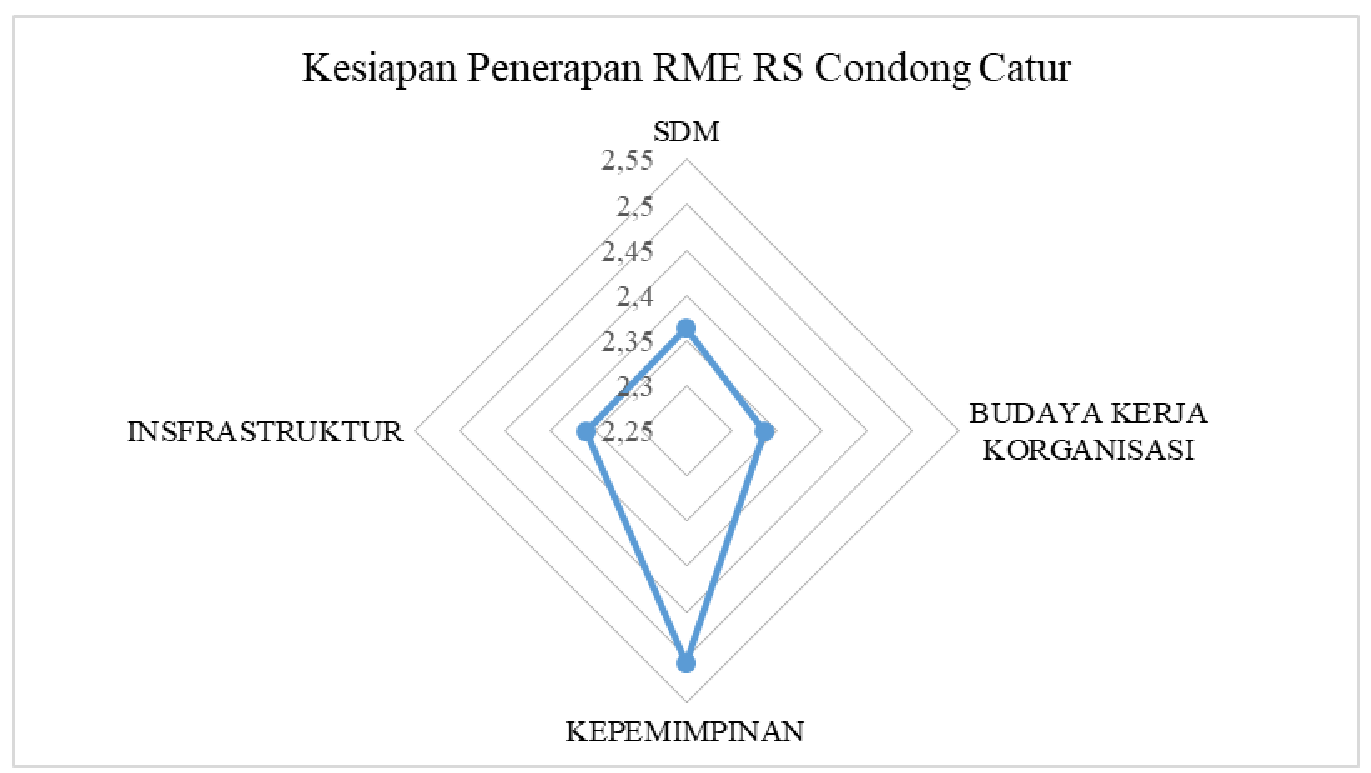

Gambar 1. Hasil analisis Kesiapan Penerapan RME RS Condong Catur

Berdasarkan gambar 1 dapat disampaikan bahwa untuk skor keseluruhan di RS Condong Catur skor keseluruhan adalah 69, skor ini masuk kategori II yaitu skor 50-97 yang mengindikasikan bahwa RS Condong Catur kuat di beberapa area kekuatan tetapi juga memiliki kelemahan di bagian lainnya. Penting untuk mengidentifikasi kekuatan di setiap bidang penilaian untuk menentukan di mana harus fokus perhatian manajerial dan perencanaan tambahan. Diperlukan identifikasi dan antisipasi lebih lanjut pada komponen yang lemah, agar implementasi bisa tetap berjalan baik [7]. Rumah sakit perlu menginformasikan proses dan mengembangkan rencana yang lebih terarah ke arah adopsi RME [12]. Oleh karena itu, kegiatan PKM ini dapat dilanjutkan kembali dengan memberikan pelatihan dan pendampingan analisis SWOT untuk mengidentifikasi konsisi lingkungan internal dan kesternal RS Condong Catur, serta berbagai faktor strategi internal (kekuatan dan kelemahan) dan eksternal (peluang dan ancaman).

Selanjutnya pada saat sesi diskusi diperoleh gambaran informasi bahwa RS Condong Catur sedang dalam proses identifikasi kebutuhan pengembangan rekam medis elektronik yang dilakukan oleh tim IT internal. Adanya dukungan dari pimpinan rumah sakit untuk mengembangan rekam medis elektronik, dilatarbelakangi karena ruang penyimpanan rekam medis yang sangat penuh, sehingga cukup berdampak dalam proses penyediaan rekam medis dan pelayanan pasien. Pengembangan RME menjadi salah satu strategi RS Condong Catur untuk meningkatkan mutu pelayanan dan mengatasi hal tersebut.

Selanjutnya pada sesi diskusi juga berlangsung dengan lancar, beberapa perserta aktif bertanya. Diantaranya direktur rumah sakit menanyakan apakah tidak bisa andaikan SIMRS berbasis rekam medis elektronik ini diterapkan dalam 
waktu 2 tahun. Diskusi terkait kebijakan dapat dilihat dari harapan yang tinggi dari pemerintah untuk mewujudkan sistem kesehatan elektronik. Arah pembangunan dan perkembangan sistem manajemen informasi kedepan tertera dalam Peraturan Menteri Kesehatan Republik Indonesia nomor 46 tahun 2017 Tentang Strategi E-Kesehatan Nasional [13].

Setelah kegiatan pengabdian kepada masyarakat ini selesai dilaksanaan. Tim pengabdian kepada masyarakat melakukan evaluasi dengan hasil sebagai berikut: (1) Kegiatan PKM yang dilaksnakan secara daring memerlukan jaringan sinyal yang bagus. Karena narasumber sempat mengalami gangguan 3 kali loss contact karena sinyal hilang; (2) Seluruh tim PKM lebih baik berada dalam satu lokasi agar koordinasinya lebih mudah ketika ada kendala sinyal.

\section{Kesimpulan}

Setelah dilaksanakan penyuluhan dan pendampingan penilaian analisis kesiapan penerapan rekam medis elektronik di Rumah Sakit Condong Catur dapat disimpulkan bahwa RS Condong Catur cukup siap untuk menerapkan aplikasi SIMRS berbasis Rekam Medis Elektronik dengan skor 69,38. Peserta menyadari bahwa perlu meningkatkan kesiapan di berbagai hal, diantaranya terkait aspek sumberdaya manusia, budaya organisasi kepemimpinan dan infrastruktur.

Kegiatan PKM ini dapat dilanjutkan kembali dengan memberikan pelatihan dan pendampingan analisis SWOT untuk mengidentifikasi kondisi lingkungan internal dan eksternal RS Condong Catur, serta berbagai faktor strategi internal (kekuatan dan kelemahan) dan eksternal (peluang dan ancaman).

\section{Ucapan terima kasih}

Terimakasih kepada Prodi RMIK (D-3) Universitas Jenderal Achmad Yani Yogyakarta yang telah memberikan dukungan dana dalam penyelenggaraan kegiatan Pengabdian kepada Masyarakat di RS Condong Catur, Sleman, DIY.

\section{Daftar pustaka}

[1] Ningsih.Kori Puspita et.al, "The Planning Of Technology-Based Emergency Minimum Service Standard Reporting System," Int. J. Heal. Educ. Soc., vol. 2, no. 9, p. 36, 2019.

[2] F. Hidayat, Sistem Informasi Kesehatan. Yogyakarta: Depublisher, 2020.

[3] Kemenkes, "Permenkes RI Nomor 82 Tahun 2013 tentang Sistem Informasi Manajamen Rumah Sakit," no. 87, pp. 1-36, 2013.

[4] Ningsih. Kori Puspita etal, "Pengembangan Pelaporan Standar Pelayanan Minimal Gawat Darurat Berbasis Web," J. Kesehat. Vokasional, vol. 4, no. 4, pp. 201-208, 2019, doi: 10.22146/jkesvo.49165.

[5] M. H. Pratama and S. Darnoto, "Analisis Strategi Pengembangan Rekam Medis Elektronik Di Instalasi Rawat Jalan Rsud Kota Yogyakarta," J. Manaj. Inf. Kesehat. Indones., vol. 5, no. 1, p. 34, 2017, doi: 10.33560/.v5i1.146.

[6] Erawatini.F, “Development Of The Doctor's Office Quality-Information Technology (DOQ-IT) In Effort To Increase Patient Security," Second Int. Conferance Food Agric., no. 269, pp. 161-166, 2020.

[7] I. Sudirahayu and A. Harjoko, "Analisis Kesiapan Penerapan Rekam Medis Elektronik Menggunakan DOQ-IT,” J. Inf. Syst. Public Heal., vol. 1, no. 2, pp. 35-43, 2016.

[8] F. Erawantini, A. Deharja, and Y. Yusfitasari, "Analisis Kesiapan Penerapan Sistem Informasi Manajemen Puskesmas(SIMPUS) Dengan Metode DOQ-IT," J. Kesehat. Politek. Negeri Jember, vol. 4, no. 1, 2016,

Praptana...........Pendampingan Penilaian Kesiapan Penerapan Rekam Medis 
[Online].

Available: https://publikasi.polije.ac.id/index.php/jurnal_kesehatan/article/view/340.

[9] A. A. Eka Wilda Faida, "Analisis Kesiapan Implementasi Rekam Medis Elektronik dengan Pendekatan DOQ-IT ( Doctor's s Office QualityInformation Technology )," J. Manaj. Inf. Kesehat. Indones., vol. 9, 2021.

[10] J. E. Hartley CP, EHR Implementation A Step by Step Guide for the Medical Practice. 2nd ed. United States: American Medical Association, 2012.

[11] Shoolin JS., "Change Management - Recommendations for Successful Electronic Medical Records.," Appl Clin Inform., pp. 286-292., 2010, doi: 10.4338/ACI-2010-01-R-0001.

[12] B. Franklin, Doctor Office Quality Information Technology. Retrieved from Doctor Office Quality Information Technology: 2021.

[13] Menkes RI, Peraturan Menteri Kesehatan No 46 Tahun 2017 Tentang Strategi E-Kesehatan Nasional. Jakarta, Indonesia, 2017. 